\title{
Concurrent capecitabine and upper abdominal radiation therapy is well tolerated
}

\author{
Prajnan Das*1, Robert A Wolff2, James L Abbruzzese ${ }^{2}$, \\ Gauri R Varadhachary², Douglas B Evans ${ }^{3}$, Jean Nicolas Vauthey33, \\ Andrew Baschnagel ${ }^{1}$, Marc E Delclos ${ }^{1}$, Sunil Krishnan ${ }^{1}$, Nora A Janjan ${ }^{1}$ and \\ Christopher H Crane ${ }^{1}$
}

\begin{abstract}
Address: ${ }^{1}$ Department of Radiation Oncology, The University of Texas M. D. Anderson Cancer Center, Houston, USA, ${ }^{2}$ Department of Gastrointestinal Medical Oncology, The University of Texas M. D. Anderson Cancer Center, Houston, USA and ${ }^{3}$ Department of Surgical Oncology, The University of Texas M. D. Anderson Cancer Center, Houston, USA

Email: Prajnan Das* - prajdas@mdanderson.org; Robert A Wolff - rwolff@mdanderson.org; James L Abbruzzese - jabbruzz@mdanderson.org; Gauri R Varadhachary - gvaradha@mdanderson.org; Douglas B Evans - devans@mdanderson.org;

Jean Nicolas Vauthey - jvauthey@mdanderson.org; Andrew Baschnagel - amb26@buffalo.edu; Marc E Delclos - mdelclos@mdanderson.org; Sunil Krishnan - skrishnan@mdanderson.org; Nora A Janjan - njanjan@mdanderson.org; Christopher H Crane - ccrane@mdanderson.org

* Corresponding author
\end{abstract}

Published: 24 October 2006

Radiation Oncology 2006, I:4I doi:|0.|I86/I748-7|7X-I-4|

This article is available from: http://www.ro-journal.com/content/I/I/4I

(C) 2006 Das et al; licensee BioMed Central Ltd.

This is an Open Access article distributed under the terms of the Creative Commons Attribution License (http://creativecommons.org/licenses/by/2.0), which permits unrestricted use, distribution, and reproduction in any medium, provided the original work is properly cited.
Received: 21 September 2006

Accepted: 24 October 2006

\begin{abstract}
We retrospectively evaluated acute toxicity in 88 patients that were treated with capecitabine and concurrent radiotherapy to the upper abdomen. These patients included $28(32 \%)$ with pancreatic adenocarcinoma, I 8 (20\%) with cholangiocarcinoma, I I (I3\%) with ampullary carcinoma, I I (I3\%) with other primary tumors, $14(16 \%)$ with liver metastases, and $6(7 \%)$ with metastases at other sites. The median dose of radiotherapy was 45 Gy (range 30-72 Gy). The median dose of capecitabine was $850 \mathrm{mg} / \mathrm{m}^{2}$ twice daily, with $77 \%$ receiving $800-900 \mathrm{mg} / \mathrm{m}^{2}$ twice daily. The highest grade of acute toxicity was Common Terminology Criteria (CTC) grade 0 in 5 (6\%), grade I in 60 (68\%), grade 2 in $18(20 \%)$, and grade 3 in $5(6 \%)$ patients. No patient had CTC grade 4 toxicity. The most common grade 2 toxicities were nausea, hand-foot syndrome, fatigue, anorexia and diarrhea. The grade 3 toxicities included nausea, vomiting and fatigue. Three patients (3\%) required hospitalization due to grade 3 acute toxicity. Capecitabine was interrupted, discontinued or given at an adjusted dose in 13 (15\%) patients because of acute toxicity. Therefore, capecitabine and concurrent radiotherapy to the upper abdomen appears to be well tolerated. Capecitabine may serve as an alternative to bolus or infusional 5 -FU during chemoradiation for upper gastrointestinal malignancies.
\end{abstract}

\section{Findings}

Capecitabine is an orally administered fluoropyrimidine that is preferentially converted to 5-FU in tumor tissue through a three-step enzymatic pathway[1]. Capecitabine is now widely used as an alternative to 5 -FU for the treat- ment of gastrointestinal cancers. Randomized trials have shown that capecitabine gives at least equivalent outcomes as 5-FU and leucovorin for the treatment of metastatic colorectal cancer, as well as for adjuvant treatment of colon cancer [2-5]. Capecitabine may serve as an alter- 
native to 5-FU for concurrent chemoradiation of gastrointestinal cancers. Phase I and II trials have shown that capecitabine is well tolerated with concurrent pelvic radiotherapy for rectal cancer, and yields pathologic complete response rates of $10-24 \%$ [6-10]. Small retrospective and prospective studies have previously reported that capecitabine is tolerated well with abdominal radiotherapy [11$14]$.

We retrospectively evaluated acute toxicity in 88 patients treated with concurrent capecitabine and radiation therapy to the upper abdomen, at the University of Texas M.D. Anderson Cancer Center, between June 2000 and July 2003. Patients who received a second concurrent chemotherapeutic agent along with capecitabine were excluded. Patients who received concurrent bevacizumab in addition to capecitabine and radiotherapy on a phase I protocol were also excluded from this study, and have been reported elsewhere[15]. The current study represents the largest reported series of patients treated with concurrent capecitabine and upper abdominal radiation therapy.

Chemoradiation was given as pre-operative treatment in $19(22 \%)$, post-operative treatment in $24(27 \%)$, definitive treatment in $5(6 \%)$, and palliation in $40(46 \%)$ patients. The median dose of radiation therapy was $45 \mathrm{~Gy}$ (range 30-72 Gy). Radiation therapy was given with 1.82 Gy fractions in 42 (48\%) patients, 2.5 Gy fractions in 15 (17\%) patients, and 3 Gy fractions in 31 (35\%) patients. Radiation therapy was delivered by 6-18 MV photons with customized blocking. A two-field technique was used for $12(14 \%)$, a three-field technique for $10(11 \%)$, a fourfield technique for $64(73 \%)$, and intensity modulated radiation therapy for $2(2 \%)$ patients.

Capecitabine was administered orally in twice-daily doses. The median dose of capecitabine was $850 \mathrm{mg} / \mathrm{m}^{2}$ (range $400-900 \mathrm{mg} / \mathrm{m}^{2}$ ) twice daily. Sixty-eight $(77 \%)$ patients received capecitabine at $800-900 \mathrm{mg} / \mathrm{m}^{2}$ twice daily. There was clear documentation that capecitabine was given 5 days a week (Monday-Friday) in 47 (53\%) patients, 6 days a week in $2(2 \%)$ and 7 days a week in 3 (3\%) patients. The frequency of capecitabine administration could not be reliably ascertained for the remaining 36 (41\%) patients.

The median age of patients was 65.5 years (range $36.5-$ 85.4 years). Of the 88 patients, $28(32 \%)$ were treated for pancreatic carcinoma, 11 (13\%) for ampullary carcinoma, 11 (13\%) for extrahepatic cholangiocarcinoma, $8(9 \%)$ for gall bladder cancer, 7 (8\%) for intrahepatic cholangiocarcinoma, 3 (3\%) for other primary tumors, $14(16 \%)$ for liver metastases, and $6(7 \%)$ for metastases at other sites.
Acute toxicity was graded using the Common Terminology Criteria for Adverse Events version 3.0. The highest grades of Common Terminology Criteria (CTC) acute toxicity during chemoradiation are shown in Table 1 . The most common grade 2 toxicities were nausea, hand-foot syndrome, fatigue, anorexia and diarrhea. The grade 3 toxicities included nausea, vomiting and fatigue. No patient had any grade 4 toxicity. The highest grade of any acute toxicity during chemoradiation was grade 0 in $5(6 \%)$, grade 1 in $60(68 \%)$, grade 2 in $18(20 \%)$, and grade 3 in $5(6 \%)$ patients.

Five patients required hospitalization during or immediately after chemoradiation, of whom $3(3 \%)$ were hospitalized due to acute toxicity. A radiation treatment break of 1 day was required in 3 patients, and radiotherapy was stopped early in 1 patient. Capecitabine administration was modified in $13(15 \%)$ patients because of acute toxicity. These modifications included discontinuation of capecitabine $(\mathrm{n}=2)$, a break in capecitabine $(\mathrm{n}=4)$, a break followed by dose reduction of capecitabine $(n=4)$, and dose reduction without a break $(n=3)$.

Our results, therefore, indicate that upper abdominal radiation therapy was well tolerated with concurrent capecitabine. Capecitabine has potential advantages over bolus or protracted infusional 5-FU for concurrent chemoradiation. Since capecitabine is orally administered, its advantages include convenience and ease of administration. Studies have demonstrated that patients prefer oral chemotherapy to intravenous chemotherapy as long as effica-

Table I: Highest Grades of Acute Toxicity During Chemoradiation

\begin{tabular}{lccc}
\hline Toxicity & \multicolumn{3}{c}{ Number of Patients (\%) } \\
\cline { 2 - 4 } & Grade I & Grade 2 & Grade 3 \\
\hline Nausea & $50(57)$ & $9(10)$ & $3(3)$ \\
Vomiting & $18(20)$ & $1(1)$ & $4(5)$ \\
Diarrhea & $22(25)$ & $3(3)$ & $0(0)$ \\
Hand-Foot Syndrome & $2(2)$ & $4(5)$ & $0(0)$ \\
Fatigue & $39(44)$ & $4(5)$ & $2(2)$ \\
Anorexia & $24(27)$ & $3(3)$ & $0(0)$ \\
Weight Loss & $12(14)$ & $1(1)$ & $0(0)$ \\
Constipation & $12(14)$ & $1(1)$ & $0(0)$ \\
Pain & $24(27)$ & $1(1)$ & $0(0)$ \\
Mucositis & $5(6)$ & $0(0)$ & $0(0)$ \\
Dehydration & $2(2)$ & $2(2)$ & $0(0)$ \\
Dysphagia & $5(6)$ & $0(0)$ & $0(0)$ \\
Heartburn & $2(2)$ & $0(0)$ & $0(0)$ \\
Skin & $7(8)$ & $0(0)$ & $0(0)$ \\
Anemia & $6(7)$ & $2(2)$ & $0(0)$ \\
Leukopenia & $1(1)$ & $0(0)$ & $0(0)$ \\
Thrombocytopenia & $3(3)$ & $0(0)$ & $0(0)$ \\
Other & $3(3)$ & $2(2)$ & $0(0)$ \\
& & &
\end{tabular}


cies are comparable $[16,17]$. Capecitabine has been shown to decrease the use of medical resources, compared to bolus 5-FU[18]. Moreover, capecitabine obviates the need for a venous catheter, which could be associated with a risk for venous thrombosis and line infections. However, since capecitabine is self-administered, its efficacy depends on patient compliance. Moreover, capecitabine is contraindicated in certain groups of patients such as those with severe renal dysfunction. Capecitabine also produces interactions with certain drugs such as coumadin and phenytoin.

Patients treated with capecitabine and concurrent chemoradiation should be monitored closely for acute toxicity. Patients who start developing acute toxicity often need adjustments in capecitabine, such as dose reduction, treatment break or discontinuation of capecitabine. As many as $15 \%$ of patients in this study underwent modifications in capecitabine during chemoradiation. Careful monitoring of patients likely played an important role in limiting the rates of acute toxicity in this study. At our institution, monitoring of these patients includes weekly blood counts and weekly assessment of diarrhea and hand-foot syndrome.

Our results are comparable to previous, smaller studies on radiation therapy with concurrent capecitabine. Vaishampayan et al. reported a retrospective study on 32 patients treated with capecitabine and radiotherapy to various sites, including abdominal radiotherapy[11]. Grade 3-4 toxicities included neutropenia in 3 patients, and diarrhea, thrombocytopenia, fatigue and myocardial infarction, each in 1 patient. Ben-Josef et al. reported a retrospective study on 15 patients with pancreatic cancer treated with concurrent capecitabine and intensity modulated radiotherapy[12]. Eight patients (53\%) had grade 12 nausea/vomiting, and only 1 patient had grade 3 toxicity. Saif et al. performed a phase I study of radiation therapy with concurrent capecitabine in 15 patients with pancreatic cancer[14]. No dose limiting toxicities were seen at capecitabine dose levels of 600 and $800 \mathrm{mg} / \mathrm{m}^{2}$ twice daily, but 2 of 6 patients experienced grade 3 diarrhea at a dose level of $1000 \mathrm{mg} / \mathrm{m}^{2}$ twice daily. Schneider et al. performed a prospective study of capecitabine and radiotherapy, preceded and followed by chemotherapy, in patients with pancreatic cancer[13]. Nineteen patients received chemoradiation in this study, of whom 1 had grade 3 nausea/vomiting, 1 had grade 3 diarrhea, 1 had grade 3 fatigue, 2 had grade 3 infectious colitis, and 1 had grade 3 rash. These studies together indicate that capecitabine is well tolerated with abdominal radiation therapy.

The current study has certain limitations. Acute toxicity was assessed retrospectively based on a review of medical records. Hence, the rates of acute toxicity may have been under-estimated. The patient population was heterogeneous with a range of tumor sites. Patients were treated with a range of radiotherapy doses and capecitabine doses. However, $77 \%$ of patients received capecitabine at $800-$ $900 \mathrm{mg} / \mathrm{m}^{2}$ twice daily, and the majority of patients received capecitabine 5 days a week, only on the days of radiotherapy.

In conclusion, this large single-institution retrospective study indicates that upper abdominal radiation therapy was well tolerated with concurrent capecitabine at a dose of $800-900 \mathrm{mg} / \mathrm{m}^{2}$ twice daily on days of radiation treatment. Only $6 \%$ of patients had grade 3 acute toxicity and no patient had grade 4 acute toxicity during chemoradiation. Moreover, only $3 \%$ of patients required hospitalization due to acute toxicity. Capecitabine may, therefore, serve as an alternative to bolus or infusional 5-FU during chemoradiation for upper gastrointestinal malignancies. Patients need to be monitored closely during chemoradiation with capecitabine, since some patients require adjustments in capecitabine dosing during chemoradiation.

\section{Competing interests disclosure}

RAW has served on the Speakers' bureau for Roche, NAJ has received research funding from Roche, and $\mathrm{CHC}$ has received honoraria from Roche.

\section{Authors' contributions}

$\mathrm{PD}$ and $\mathrm{CHC}$ conceived of the study, coordinated the study and helped to draft the manuscript. $\mathrm{AB}$ participated in data analysis. RAW, JLA, GRV, DBE, JNV, AB, MED, SK, and NAJ participated in data collection. All authors read and approved the final manuscript.

\section{References}

I. Miwa M, Ura M, Nishida M, Sawada N, Ishikawa T, Mori K, Shimma N, Umeda I, Ishitsuka $\mathrm{H}$ : Design of a novel oral fluoropyrimidine carbamate, capecitabine, which generates 5-fluorouracil selectively in tumours by enzymes concentrated in human liver and cancer tissue. Eur J Cancer 1998, 34: I 274-I28I.

2. Van Cutsem E, Findlay M, Osterwalder B, Kocha W, Dalley D, Pazdur R, Cassidy J, Dirix L, Twelves C, Allman D, Seitz JF, Scholmerich J, Burger HU, Verweij J: Capecitabine, an oral fluoropyrimidine carbamate with substantial activity in advanced colorectal cancer: results of a randomized phase II study. J Clin Oncol 2000, 18:1337-1345.

3. Hoff PM, Ansari R, Batist G, Cox J, Kocha W, Kuperminc M, Maroun J, Walde D, Weaver C, Harrison E, Burger HU, Osterwalder B, Wong AO, Wong R: Comparison of oral capecitabine versus intravenous fluorouracil plus leucovorin as first-line treatment in $\mathbf{6 0 5}$ patients with metastatic colorectal cancer: results of a randomized phase III study. J Clin Oncol 200I, 1 9:2282-2292.

4. Cassidy J, Twelves C, Van Cutsem E, Hoff P, Bajetta E, Boyer M, Bugat R, Burger U, Garin A, Graeven U, McKendric J, Maroun J, Marshall J, Osterwalder B, Perez-Manga G, Rosso R, Rougier P, Schilsky RL: First-line oral capecitabine therapy in metastatic colorectal cancer: a favorable safety profile compared with intravenous 5-fluorouracil/leucovorin. Ann Oncol 2002, 1 3:566-575.

5. Twelves C, Wong A, Nowacki MP, Abt M, Burris H 3rd, Carrato A, Cassidy J, Cervantes A, Fagerberg J, Georgoulias V, Husseini F, Jodrell 
D, Koralewski P, Kroning H, Maroun J, Marschner N, McKendrick J, Pawlicki M, Rosso R, Schuller J, Seitz JF, Stabuc B, Tujakowski J, Van Hazel G, Zaluski J, Scheithauer W: Capecitabine as adjuvant treatment for stage III colon cancer. N Engl J Med 2005, 352:2696-2704.

6. Dunst J, Reese T, Sutter T, Zuhlke H, Hinke A, Kolling-Schlebusch K, Frings S: Phase I trial evaluating the concurrent combination of radiotherapy and capecitabine in rectal cancer. I Clin Oncol 2002, 20(19):3983-3991.

7. Ngan SY, Michael M, Mackay J, McKendrick J, Leong T, Lim Joon D, Zalcberg JR: A phase I trial of preoperative radiotherapy and capecitabine for locally advanced, potentially resectable rectal cancer. BrJ Cancer 2004, 91:1019-1024.

8. De Paoli A, Chiara S, Luppi G, Friso ML, Beretta GD, Del Prete $S$, Pasetto L, Santantonio M, Sarti E, Mantello G, Innocente R, Frustaci S, Corvo R, Rosso R: Capecitabine in combination with preoperative radiation therapy in locally advanced, resectable, rectal cancer: a multicentric phase II study. Ann Oncol 2005.

9. Kim JC, Kim TW, Kim JH, Yu CS, Kim HC, Chang HM, Ryu MH, Park JH, Ahn SD, Lee SW, Shin SS, Kim JS, Choi EK: Preoperative concurrent radiotherapy with capecitabine before total mesorectal excision in locally advanced rectal cancer. Int J Radiat Oncol Biol Phys 2005, 63:346-353.

10. Krishnan S, Janjan NA, Skibber JM, Rodriguez-Bigas RA, Wolff C, Das P, Delclos ME, Chang GJ, Hoff PM, Eng C, Brown TD, Crane CH, Feig BW, Morris J, Vadhan-Raj S, Hamilton SR, Lin EH: A phase II study of capecitabine and concomitant boost radiotherapy in patients with locally advanced rectal cancer. Int J Radiat Oncol Biol Phys 2006, 66(3):762-7I.

II. Vaishampayan UN, Ben-Josef E, Philip PA, Vaitkevicius VK, Du W, Levin KJ, Shields AF: A single-institution experience with concurrent capecitabine and radiation therapy in gastrointestinal malignancies. Int J Radiat Oncol Biol Phys 2002, 53:675-679.

12. Ben-Josef E, Shields AF, Vaishampayan U, Vaitkevicius V, El-Rayes BF, McDermott P, Burmeister J, Bossenberger T, Philip PA: Intensitymodulated radiotherapy (IMRT) and concurrent capecitabine for pancreatic cancer. Int J Radiat Oncol Biol Phys 2004, 59(2):454-459.

13. Schneider BJ, Ben-Josef E, McGinn CJ, Chang AE, Colletti LM, NormoIle DP, Hejna GF, Lawrence TS, Zalupski MM: Capecitabine and radiation therapy preceded and followed by combination chemotherapy in advanced pancreatic cancer. Int J Radiat Oncol Biol Phys 2005, 63(5): 1325-30.

14. Saif MW, Eloubeidi MA, Russo S, Steg A, Thornton J, Fiveash J, Carpenter M, Blanquicett C, Diasio RB, Johnson MR: Phase I study of capecitabine with concomitant radiotherapy for patients with locally advanced pancreatic cancer: expression analysis of genes related to outcome. J Clin Oncol 2005, 23:8679-8687.

15. Crane CH, Ellis LM, Abbruzzese JL, Amos C, Xiong HQ, Ho L, Evans DB, Tamm EP, Ng C, Pisters PWT, Charnsangavej C, Delclos ME, O'Reilly M, Lee JE, Wolff RA: Phase I Trial Evaluating the Safety of Bevacizumab With Concurrent Radiotherapy and Capecitabine in Locally Advanced Pancreatic Cancer. J Clin Oncol 2006, 24: I|45-II5I.

16. Liu G, Franssen E, Fitch MI, Warner E: Patient preferences for oral versus intravenous palliative chemotherapy. J Clin Oncol 1997, I5:110-115.

17. Borner MM, Schoffski P, de Wit R, Caponigro F, Comella G, Sulkes A, Greim G, Peters G], van der Born K, Wanders J, de Boer RF, Martin $C$, Fumoleau P: Patient preference and pharmacokinetics of oral modulated UFT versus intravenous fluorouracil and leucovorin: a randomised crossover trial in advanced colorectal cancer. Eur J Cancer 2002, 38:349-358.

18. Twelves C, Boyer M, Findlay M, Cassidy J, Weitzel C, Barker C, Osterwalder B, Jamieson C, Hieke K: Capecitabine (Xeloda) improves medical resource use compared with 5-fluorouracil plus leucovorin in a phase III trial conducted in patients with advanced colorectal carcinoma. Eur J Cancer 200I, 37:597-604.

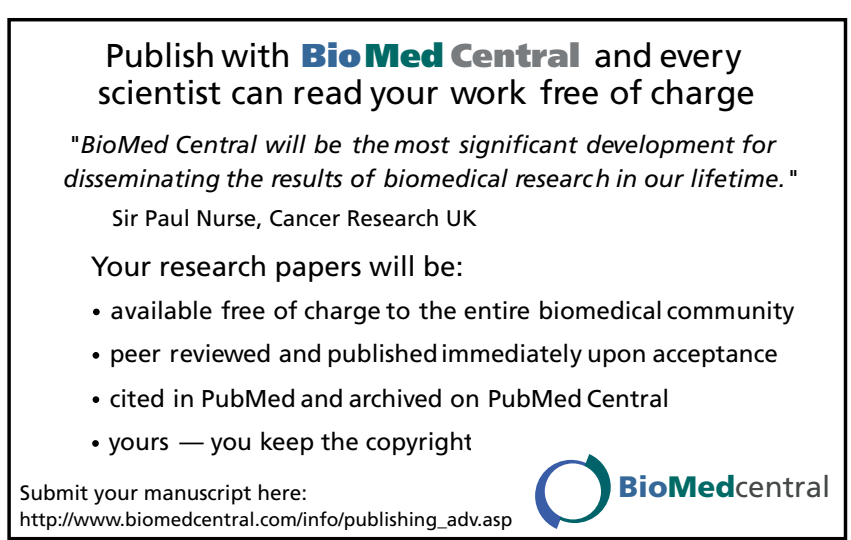

